\title{
The Influence of Annealing on the Structural and Soft Magnetic Properties of $\left(\mathrm{Fe}_{0.4} \mathrm{Co}_{0.6}\right)_{79} \mathrm{Nb}_{3} \mathrm{~B}_{18}$ Nanocrystalline Alloys
}

\author{
Man Zhu *, Yang Fa, Lijuan Yao, Peng Tao, Zengyun Jian and Fang'e Chang \\ School of Materials Science and Chemical Engineering, Xi'an Technological University, Xi'an 710021, China; \\ fayang2025@163.com (Y.F.); ylj8453@126.com (L.Y.); 18762794998@126.com (P.T.); jianzengyun@xatu.edu.cn (Z.J.); \\ cfe.ch@163.com (F.C.) \\ * Correspondence: zhuman0428@126.com; Tel.: +86-029-8617-3324
}

Received: 4 October 2018; Accepted: 30 October 2018; Published: 2 November 2018

\begin{abstract}
The soft magnetic properties of Fe-based nanocrystalline alloys are determined by their grain size. In the present article, the $\left(\mathrm{Fe}_{0.4} \mathrm{Co}_{0.6}\right)_{79} \mathrm{Nb}_{3} \mathrm{~B}_{18}$ nanocrystalline alloys have been successfully prepared by isothermal annealing. The variation of soft magnetic properties as a function of annealing temperature and incubation time is investigated in detail. Two distinct crystallization behaviors were found for the $\left(\mathrm{Fe}_{0.4} \mathrm{Co}_{0.6}\right)_{79} \mathrm{Nb}_{3} \mathrm{~B}_{18}$ alloys. The initial nanocrystallization products comprise a mixture of $\alpha$ - $\mathrm{Fe}(\mathrm{Co}), \mathrm{Fe}_{2} \mathrm{~B}$, and $\mathrm{Fe}_{23} \mathrm{~B}_{6}$-type crystalline metastable phases, and the final crystallization products are composed of $\alpha-\mathrm{Fe}(\mathrm{Co}), \mathrm{Fe}_{2} \mathrm{~B}$, and $\mathrm{Fe}_{3} \mathrm{~B}$ crystalline phases. The grain size decreases first and then increases with the increasing annealing temperature in the range of 764-1151 K, and a fine grain size with mean grain size of $12.7 \mathrm{~nm}$ can be achieved for alloys annealed at $880 \mathrm{~K}$. As the annealing temperature increases from $764 \mathrm{~K}$ to $1151 \mathrm{~K}$, the saturation magnetization increases first and then decreases without a significant increase of the coercivity. The alloys annealed at $880 \mathrm{~K}$ exhibit the optimized soft magnetic properties with high $M_{\mathrm{s}}$ of $145 \mathrm{emu} \mathrm{g} \mathrm{g}^{-1}$ and low $H_{\mathrm{c}}$ of 0.04 Oe.
\end{abstract}

Keywords: Fe-based nanocrystalline alloys; isothermal annealing; grain size; soft magnetic properties

\section{Introduction}

In 1988, Yoshizawa et al. [1] developed a new series of $\mathrm{FeCuNbSiB}$ nanocrystalline alloys with excellent magnetic properties. In 2013, Rizal et al. [2] artificially produced Fe-Co alloys with record high saturation magnetization $\left(M_{\mathrm{S}}>240 \mathrm{emu} / \mathrm{g}\right)$. This group claimed that the increase of $M_{\mathrm{S}}$ is correlated with the increase of the lattice constant of the alloy. Thus, these Fe-based soft magnetic alloys have received great attention in the materials field [3-5]. The Fe-based nanocrystalline alloys with high performance have been served as the magnetic cores, sensors, and transformers in electrical industrial fields, and they are potential candidates to replace traditional soft magnetic alloys, such as silicon steel and ferrite. Generally speaking, metallic glass is in a thermodynamically metastable state. Upon heating, it would transform into a stable state by a crystallization process to form amorphous/nanocrystalline alloys. The soft magnetic properties in the Fe-based nanocrystalline alloys are determined by the type and grain size of the nano-scale precipitates. Nowadays, annealing crystallization is one of the key methods used to prepare Fe-based nanocrystalline alloys [6-10]. Therefore, it is of theoretical significance and engineering application value to explore the relationship between their magnetic properties and annealing process. Generally speaking, the grain size increases with increasing annealing temperature [11-13]. However, according to recent studies, as the annealing temperature increases, the grain size increases first, then decreases, and increases again in the Fe-based nanocrystalline alloys [14,15]. Xue et al. [14] pointed out that the grain size reaches the minimum 
value for the $\mathrm{Fe}_{83} \mathrm{Nb}_{2} \mathrm{~B}_{14} \mathrm{Cu}_{1}$ alloys annealed at $813 \mathrm{~K}$, while their saturation magnetization increases steadily from $1.4 \mathrm{~T}$ to $1.7 \mathrm{~T}$ with the increase of annealing temperature. Li et al. [15] pointed out that the $\mathrm{Fe}_{73.37} \mathrm{Cu}_{0.92} \mathrm{Nb}_{2.9} \mathrm{Si}_{13.56} \mathrm{~B}_{9.24}$ nanocrystalline alloys with the finest grain size exhibited optimized magnetic properties. However, the experiments carried out by Jiang et al. [16] indicated that the grain size in the $\mathrm{Fe}_{73.5} \mathrm{Cu}_{1} \mathrm{Nb}_{3} \mathrm{Si}_{13.5} \mathrm{~B}_{9}$ nanocrystalline alloys decreases slightly, and then increases with increasing annealing temperature, and the anomalous grain growth is ascribed to the different nucleation and volume diffusion rates at varied annealing temperatures. The variation of grain size as a function of annealing during the annealing process remains unclear, and it is quite difficult to determine the optimized annealing process for alloys with excellent soft magnetic properties. It is accepted that fine and well-distributed nanoscale precipitates within the amorphous matrix are of benefit to enhance the magnetic properties. Thus, it is of great importance to study the relationship between magnetic properties and the annealing process.

In this article, the aim is to explore the relationship between grain size and annealing temperature in the $\left(\mathrm{Fe}_{0.4} \mathrm{Co}_{0.6}\right)_{79} \mathrm{Nb}_{3} \mathrm{~B}_{18}$ alloys. In addition, the soft magnetic properties as a function of the kinds and size of the precipitates are also studied, which can provide theoretical guidance for the development of Fe-based nanocrystalline alloys with excellent soft magnetic properties.

\section{Materials and Methods}

Master alloy ingots with nominal composition of $\left(\mathrm{Fe}_{0.4} \mathrm{Co}_{0.6}\right)_{79} \mathrm{Nb}_{3} \mathrm{~B}_{18}$ were prepared by induction melting (SPG-40B high frequency induction heating equipment, Shenzhen, China) the mixture of pure Co $(99.98 w t \%), F e(99.8 w t \%), F e-60 w t \% ~ N b$ and Fe-17.5 wt \% B master alloy. Then, the amorphous ribbons were prepared by melt-spinning method under high vacuum single-roller spinning equipment. During this process, the linear velocity and ejection pressure are $40 \mathrm{~m} / \mathrm{s}$ and $20 \mathrm{kPa}$, respectively. The resulting ribbons have a thickness of 20-30 $\mu \mathrm{m}$. Then, the isothermal annealing experiment was performed for the glassy ribbons sealed into quartz tubes under vacuum condition $\left(4 \times 10^{-3} \mathrm{~Pa}\right)$ in a resistance furnace. The annealing temperature $\left(T_{\mathrm{a}}\right)$ was set as $764 \mathrm{~K}, 800 \mathrm{~K}, 880 \mathrm{~K}, 974 \mathrm{~K}$, and $1151 \mathrm{~K}$.

Phase constitution was identified by X-ray diffractometer (XRD; Bruker D8 advance, Bruker AXS GmbH, Karlsruhe, Germany) with $\mathrm{Cu} \mathrm{K} \alpha$ as a radiation $(\lambda=0.154056 \mathrm{~nm})$ in steps of $0.02^{\circ}$ in the $2 \theta=30-120^{\circ}$. Thermal behaviors of the glassy ribbons were studied using differential scanning calorimetry (DSC; Mettler-Toledo TGA/DSC1, Mettler-Toledo International Inc., Zurich, Switzerland) at a continuous heating rate of $40 \mathrm{~K} \mathrm{~min}^{-1}$. Room-temperature magnetic hysteresis loops were measured using a vibrating sample magnetometer (VSM; Lake Shore 7410, Lake Shore Cryotronics, Columbus, OH, USA) under an applied magnetic field of 10,000 Oe.

\section{Results and Discussion}

\subsection{Structure Identification and Thermal Properties in the As-Quenched $\left(\mathrm{Fe}_{0.4} \mathrm{Co}_{0.6}\right)_{79} \mathrm{Nb}_{3} \mathrm{~B}_{18}$ Alloys}

Figure 1a shows the XRD pattern taken from the as-quenched $\left(\mathrm{Fe}_{0.4} \mathrm{Co}_{0.6}\right)_{79} \mathrm{Nb}_{3} \mathrm{~B}_{18}$ alloys. Only a wide diffraction peak in the $2 \theta$ region of $35-55^{\circ}$ can be observed, and no sharp Bragg diffraction peaks corresponding to the crystalline phases are detected. This is the typical characteristic of amorphous alloys, indicating that a fully amorphous structure is obtained in the $\left(\mathrm{Fe}_{0.4} \mathrm{Co}_{0.6}\right)_{79} \mathrm{Nb}_{3} \mathrm{~B}_{18}$ alloys.

Figure $1 \mathrm{~b}$ displays the DSC heating trace of the as-quenched $\left(\mathrm{Fe}_{0.4} \mathrm{Co}_{0.6}\right)_{79} \mathrm{Nb}_{3} \mathrm{~B}_{18}$ alloys with a constant heating rate of $40 \mathrm{~K} \mathrm{~min}^{-1}$. During the heating process, it undergoes a glass transition event followed by a supercooled liquid region, and then two-stage crystallization events are observed. The value of glass transition temperature $\left(T_{\mathrm{g}}\right)$ is equal to $732 \mathrm{~K}$, and the values of first crystallization onset temperature $\left(T_{x 1}\right)$ and second crystallization onset temperature $\left(T_{x 2}\right)$ are equal to $786 \mathrm{~K}$ and $887 \mathrm{~K}$, respectively. The supercooled liquid region $\Delta T_{\mathrm{x}}=T_{\mathrm{x} 1}-T_{\mathrm{g}}$, is estimated to be $54 \mathrm{~K}$. In the high-temperature region, there are two endothermic peaks. The values of solidus temperature $\left(T_{\mathrm{m}}\right)$ and liquidus temperature $\left(T_{1}\right)$ are $1219 \mathrm{~K}$ and $1444 \mathrm{~K}$, respectively. The parameter $T_{r g}\left(=T_{\mathrm{g}} / T_{1}\right)$ is calculated to be 0.507 . The results suggest that present $\left(\mathrm{Fe}_{0.4} \mathrm{Co}_{0.6}\right)_{79} \mathrm{Nb}_{3} \mathrm{~B}_{18}$ alloys possess high glass forming 
ability (GFA). The temperature intervals $\Delta T_{\mathrm{N}}$ between two crystalline peaks, defined as $T_{\mathrm{x} 2}-T_{\mathrm{x} 1}$, reach $101 \mathrm{~K}$. It is reported that large $\Delta T_{\mathrm{N}}$ is of benefit to the fabrication of amorphous/nanocrystalline alloys by precisely controlling the annealing process.

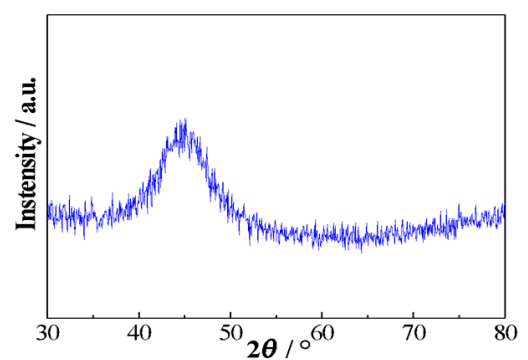

(a)

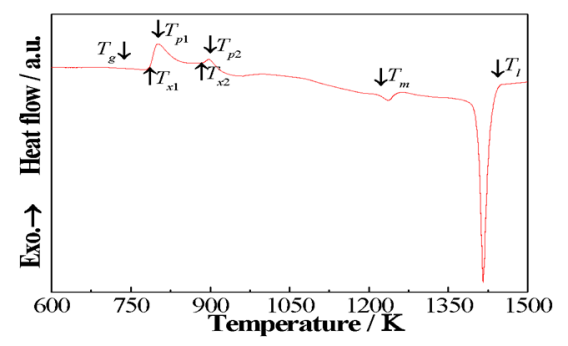

(b)

Figure 1. XRD pattern (a) and DSC heating curve (b) of the as-quenched $\left(\mathrm{Fe}_{0.4} \mathrm{Co}_{0.6}\right)_{79} \mathrm{Nb}_{3} \mathrm{~B}_{18}$ alloys.

\subsection{Structural Evolution in the Annealed $\left(\mathrm{Fe}_{0.4} \mathrm{Co}_{0.6}\right)_{79} \mathrm{Nb}_{3} \mathrm{~B}_{18}$ Alloys}

The $\left(\mathrm{Fe}_{0.4} \mathrm{Co}_{0.6}\right)_{79} \mathrm{Nb}_{3} \mathrm{~B}_{18}$ alloys were isothermally annealed at a temperature of $T_{\mathrm{a}}=764 \mathrm{~K}$, which is near $T_{\mathrm{x} 1}$ between $T_{\mathrm{g}}$ and $T_{\mathrm{x} 1}$. Figure 2 exhibits the XRD patterns of the $\left(\mathrm{Fe}_{0.4} \mathrm{Co}_{0.6}\right)_{79} \mathrm{Nb}_{3} \mathrm{~B}_{18}$ alloys annealed at $764 \mathrm{~K}$ for different incubation times. The crystallization products are composed of $\alpha-\mathrm{Fe}(\mathrm{Co})$, $\mathrm{Fe}_{2} \mathrm{~B}$, and $\mathrm{Fe}_{23} \mathrm{~B}_{6}$ phases for alloys annealed for $60 \mathrm{~s}$. As the incubation time increases from $90 \mathrm{~s}$ to $900 \mathrm{~s}$, the crystallization products still remain unchanged. The results indicate that increasing incubation time cannot change the crystallization process.

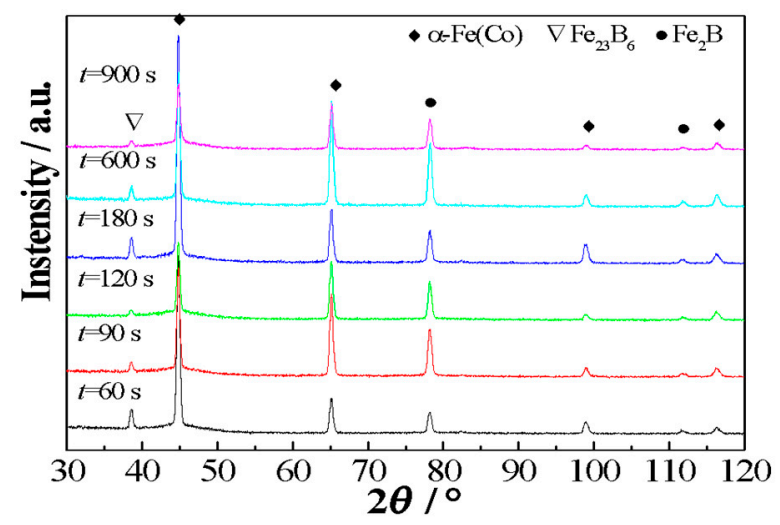

Figure 2. XRD patterns of the $\left(\mathrm{Fe}_{0.4} \mathrm{Co}_{0.6}\right)_{79} \mathrm{Nb}_{3} \mathrm{~B}_{18}$ alloys annealed at $764 \mathrm{~K}$ for varied times.

Figure 3 displays the XRD patterns of the $\left(\mathrm{Fe}_{0.4} \mathrm{Co}_{0.6}\right)_{79} \mathrm{Nb}_{3} \mathrm{~B}_{18}$ alloys annealed at $764 \mathrm{~K}, 800 \mathrm{~K}$, $880 \mathrm{~K}, 974 \mathrm{~K}$, and $1151 \mathrm{~K}$ for $90 \mathrm{~s}$, respectively. For alloys annealed at $764 \mathrm{~K}$, the crystallization products consist of a mixture of $\alpha-\mathrm{Fe}(\mathrm{Co}), \mathrm{Fe}_{23} \mathrm{~B}_{6}$, and $\mathrm{Fe}_{2} \mathrm{~B}$ phases. The formation of a metastable $\mathrm{Fe}_{23} \mathrm{~B}_{6}$ phase was previously reported in the FeNbB ternary alloys [3,17-19]. It has an $f_{c c}$ structure with a lattice constant of $a=1.076 \mathrm{~nm}$. In this structure, the cubo-octahedra and the cubes formed by metal atoms are symmetrically connected with metalloid atoms. Thus, it would prevent long-range ordered diffusion during the solidification process, which favors the enhancement of GFA. For the alloys annealed at $800 \mathrm{~K}$ and $880 \mathrm{~K}$, which range from $T_{\mathrm{x} 1}$ to $T_{\mathrm{x} 2}$, the crystallization products remain unchanged, and they are composed of $\alpha-\mathrm{Fe}(\mathrm{Co}), \mathrm{Fe}_{23} \mathrm{~B}_{6}$, and $\mathrm{Fe}_{2} \mathrm{~B}$ phases. Because of the relatively short incubation time, the $\mathrm{Fe}_{23} \mathrm{~B}_{6}$ phase is not completely decomposed. Thus, the existence of the metastable $\mathrm{Fe}_{23} \mathrm{~B}_{6}$ phase still can be detected in the XRD patterns. Although the crystallization products remain unchanged, the corresponding width and intensity of the Bragg diffraction peaks change. This phenomenon suggests that the $\alpha-\mathrm{Fe}(\mathrm{Co}), \mathrm{Fe}_{23} \mathrm{~B}_{6}$, and $\mathrm{Fe}_{2} \mathrm{~B}$ phases undergo grain growth processes, and their volume fraction increases. When the annealing temperature is larger than $T_{\mathrm{p} 2}$, the crystallization products consist of 
$\alpha-\mathrm{Fe}(\mathrm{Co}), \mathrm{Fe}_{2} \mathrm{~B}$, and $\mathrm{Fe}_{3} \mathrm{~B}$ phases for alloys annealed at $974 \mathrm{~K}$. The existence of $\mathrm{Fe}_{2} \mathrm{~B}$ and $\mathrm{Fe}_{3} \mathrm{~B}$ phases is attributed to the decomposition of the metastable $\mathrm{Fe}_{23} \mathrm{~B}_{6}$ phase. As the annealing temperature is further increased to $1151 \mathrm{~K}$, the crystallization products remain composed of $\alpha-\mathrm{Fe}(\mathrm{Co}), \mathrm{Fe}_{2} \mathrm{~B}$, and $\mathrm{Fe}_{3} \mathrm{~B}$ phases. The amount of relative diffraction peaks of $\mathrm{Fe}_{2} \mathrm{~B}$ and $\mathrm{Fe}_{3} \mathrm{~B}$ phases is increased, suggesting that the volume fractions of $\mathrm{Fe}_{2} \mathrm{~B}$ and $\mathrm{Fe}_{3} \mathrm{~B}$ phases are enhanced. Therefore, the crystallization processes in the $\left(\mathrm{Fe}_{0.4} \mathrm{Co}_{0.6}\right)_{79} \mathrm{Nb}_{3} \mathrm{~B}_{18}$ alloys can be expressed as:

$$
\text { Amorphous } \rightarrow \text { Amorphous }+\alpha-\mathrm{Fe}(\mathrm{Co})+\mathrm{Fe}_{23} \mathrm{~B}_{6}+\mathrm{Fe}_{2} \mathrm{~B} \rightarrow \alpha \text { - } \mathrm{Fe}(\mathrm{Co})+\mathrm{Fe}_{2} \mathrm{~B}+\mathrm{Fe}_{3} \mathrm{~B}
$$

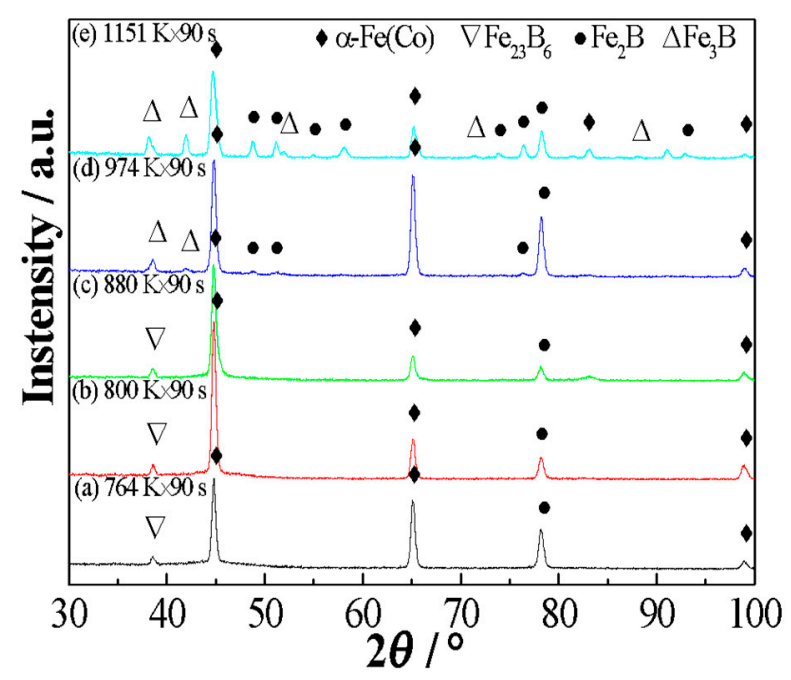

Figure 3. Structural evolution of the $\left(\mathrm{Fe}_{0.4} \mathrm{Co}_{0.6}\right)_{79} \mathrm{Nb}_{3} \mathrm{~B}_{18}$ alloys annealed at different temperatures for $90 \mathrm{s.}$

The crystallinity refers to the degree of crystallization of amorphous alloys under different heat treatment processes. The crystallinity, $X_{c}$, can be expressed as,

$$
X_{\mathrm{c}}=\frac{W_{\mathrm{c}}}{W_{\mathrm{c}}+W_{\mathrm{A}}},
$$

where $W_{\mathrm{c}}$ and $W_{\mathrm{A}}$ represent the mass fraction of the crystalline phase and amorphous phase, respectively.

Figure 4 shows the relationship between crystallinity $X_{\mathrm{c}}$ and annealing temperature $T_{\mathrm{a}}$. The value of $X_{\mathrm{c}}$ is equal to $68.69 \%$ for alloys annealed at $764 \mathrm{~K}$. With the increase of the annealing temperature, the crystallinity increases steadily. As the annealing temperature is further increased to $1151 \mathrm{~K}$, the value of $X_{c}$ becomes $98.88 \%$.

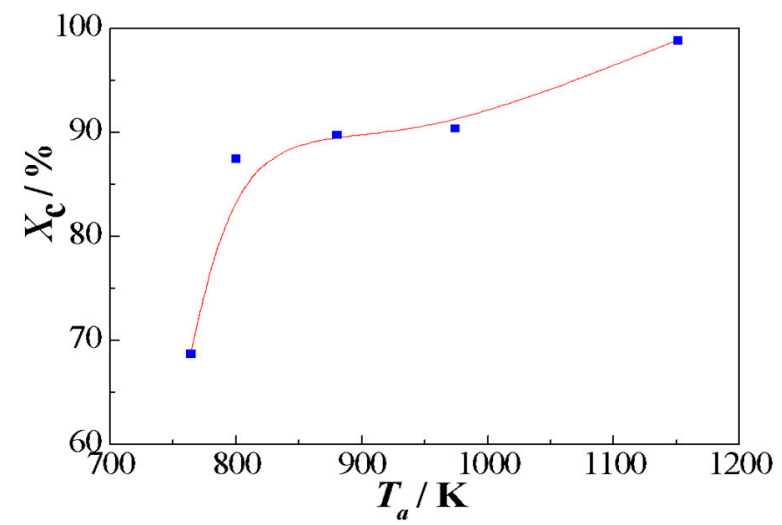

Figure 4. Variation of crystallinity as a function of annealing temperature for the $\left(\mathrm{Fe}_{0.4} \mathrm{Co}_{0.6}\right)_{79} \mathrm{Nb}_{3} \mathrm{~B}_{18}$ alloys. 


\subsection{Variation of Grain Size and Annealing Temperature}

According to the Scherrer Equation [6], the mean grain size $(D)$ of the crystallite can be expressed as:

$$
D=\frac{\mathrm{k} \lambda}{\beta \cos \theta},
$$

where $\lambda$ is wavelength, $\theta$ is half the diffraction angle, $\beta$ is full-width at half-maximum (FWHM) of the diffraction peak, and $\mathrm{k}$ is the constant $(\mathrm{k}=0.89)$.

The mean grain size $(D)$ as a function of annealing temperature is plotted in Figure 5, and the corresponding DSC curve is also given. With the increase of the annealing temperature within the range $764-1151 \mathrm{~K}$, the mean grain size decreases steadily and then increases. In other words, the grain size has obvious valley value with the change of the annealing temperature. The mean grain size $(D)$ is equal to $18.2 \mathrm{~nm}$ and $17.7 \mathrm{~nm}$ for alloys annealed at $764 \mathrm{~K}$ and $1151 \mathrm{~K}$, respectively. It reaches the minimum value of $12.7 \mathrm{~nm}$ for alloys annealed at $880 \mathrm{~K}$.

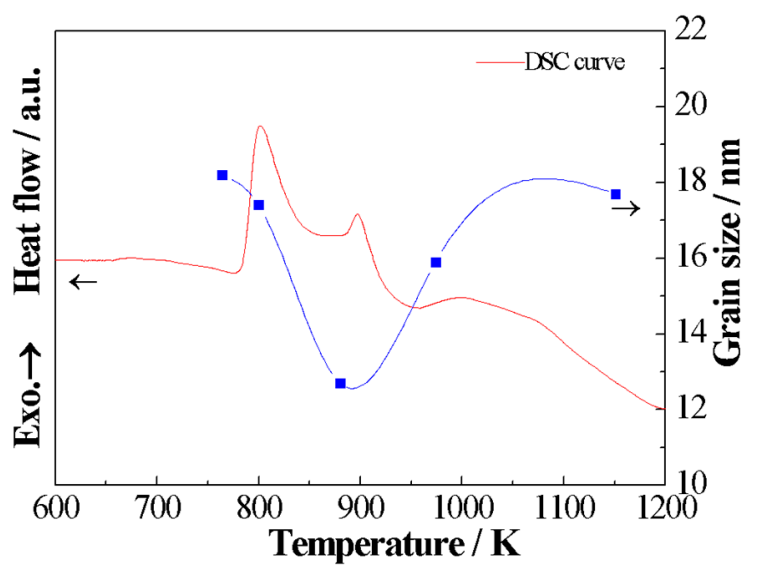

Figure 5. The relationship between mean grain size and annealing temperature for the $\left(\mathrm{Fe}_{0.4} \mathrm{Co}_{0.6}\right)_{79} \mathrm{Nb}_{3} \mathrm{~B}_{18}$ alloys.

The relationship between mean grain size and annealing temperature is in accordance with that predicted by theoretical analysis $[20,21]$. In other words, when the annealing temperature is equal to $0.6 T_{\mathrm{m}}$, the mean grain size reaches the minimum value. It is directly related to the combined effect of a high nucleation rate and low grain growth rate. The crystallization process includes nucleation and grain growth processes. The nucleation rate $I\left(T_{a}\right)$ and grain growth rate $U\left(T_{a}\right)$ can be expressed as [20,22]:

$$
\begin{gathered}
I\left(T_{a}\right)=I_{0} \exp \left(-\frac{\lambda \Delta S_{m}^{f}}{R \tau^{2}(1-\tau)^{3}}\right) \exp \left(-\frac{\Delta E_{n}}{R T_{a}}\right), \\
U\left(T_{a}\right)=U_{0}\left[1-\exp \left(-\frac{\Delta S_{m}^{f} \tau}{R(1-\tau)}\right)\right] \exp \left(-\frac{\Delta E_{g}}{R T_{a}}\right),
\end{gathered}
$$

where $\Delta S_{m}^{f}$ is melting entropy, $\tau\left(=1-T_{a} / T_{m}\right)$ the undercooling, $R$ the gas constant, $\Delta E_{n}$ the activation energy of nucleation, $\Delta E_{g}$ the activation energy of diffusion, $T_{a}$ the annealing temperature, $T_{m}$ the melting temperature, and $I_{0}, U_{0}$, and $\lambda$ are the constants.

It can be found that the nucleation rate $I\left(T_{a}\right)$ is determined by $T_{a}$ and $\Delta E_{n}$, and grain growth rate $U\left(T_{a}\right)$ is associated with $T_{a}$ and $\Delta E_{g}$. The relationship between the nucleation rate and grain growth rate and annealing temperature is schematically plotted in Figure 6 [6], and $T_{x}$ and $T_{m}$ represent the first crystalline temperature and melting point, respectively. With the increase of $T_{a}, I\left(T_{a}\right)$ and $U\left(T_{a}\right)$ increase first and then decrease. As the temperature increases from the first crystalline temperature to the temperature of the extreme value of the nucleation rate, the nucleation rate increases faster than the grain growth rate, and it reaches the extreme value quickly. Previous theoretical research confirmed 
that, when the annealing temperature is equal to approximately $0.6 T_{m}$, a high nucleation rate and low grain growth rate can be achieved. Thus, it is reasonable to believe that the nanocrystalline alloys with fine grain sizes can be obtained for alloys annealed in the vicinity of $0.6 T_{m}$.

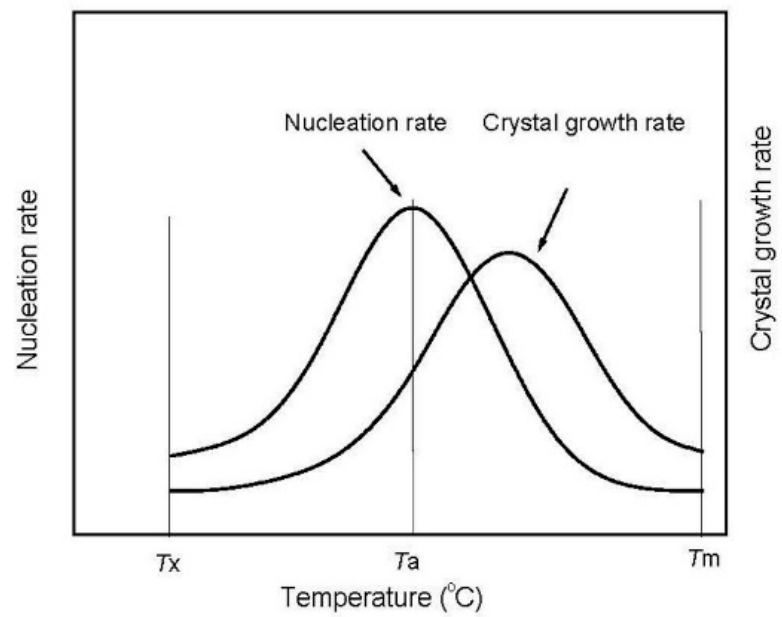

Figure 6. Schematic diagram showing the plots of nucleation rate and grain growth rate as a function of annealing temperature.

\subsection{Soft Magnetic Properties}

Figure 7a displays the room-temperature magnetization hysteresis curves $(M-H)$ of the $\left(\mathrm{Fe}_{0.4} \mathrm{Co}_{0.6}\right)_{79} \mathrm{Nb}_{3} \mathrm{~B}_{18}$ alloys annealed at $764 \mathrm{~K}$ for $60-900 \mathrm{~s}$, and the inset shows the enlarged image of the $M-H$ curves. As can be seen from Figure $7 \mathrm{a}$, the annealed alloys exhibit obvious soft magnetic properties without a significant increase of the coercivity. Figure $7 \mathrm{~b}$ exhibits the relationship between saturation magnetization $\left(M_{\mathrm{S}}\right)$ and coercivity $\left(H_{\mathrm{c}}\right)$ and incubation time $(t)$ in the $\left(\mathrm{Fe}_{0.4} \mathrm{Co}_{0.6}\right)_{79} \mathrm{Nb}_{3} \mathrm{~B}_{18}$ alloys. The $M_{\mathrm{S}}$ value is equal to $113 \mathrm{emu} \mathrm{\textrm {g } ^ { - 1 }}$ for the as-quenched $\left(\mathrm{Fe}_{0.4} \mathrm{Co}_{0.6}\right)_{79} \mathrm{Nb}_{3} \mathrm{~B}_{18}$ alloys. Annealing for $60 \mathrm{~s}$ does not result in a significant change in $M_{\mathrm{s}}$. As the incubation time further increases, the $M_{\mathrm{s}}$ value increases steadily. When the incubation time is equal to $900 \mathrm{~s}$, the $M_{\mathrm{s}}$ value reaches the maximum value of $132 \mathrm{emu} \mathrm{g}^{-1}$. The increase of the $M_{\mathrm{s}}$ value is mainly determined by the grain size and volume fraction of the nano-scale precipitates. However, as the incubation time increases, the $H_{\mathrm{c}}$ value decreases slightly and then increases, and reaches 0.56 Oe for alloys annealed for $900 \mathrm{~s}$. Short-time annealing benefits the reduction of internal stress, resulting in a slight decrease of $M_{\mathrm{s}}$. However, further annealing leads to an increase in grain size, resulting in high $M_{\mathrm{s}}$.

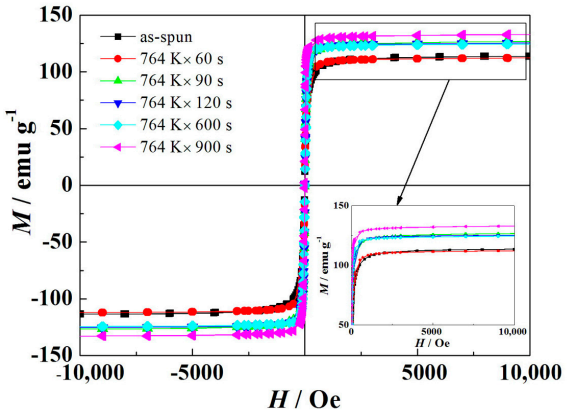

(a)

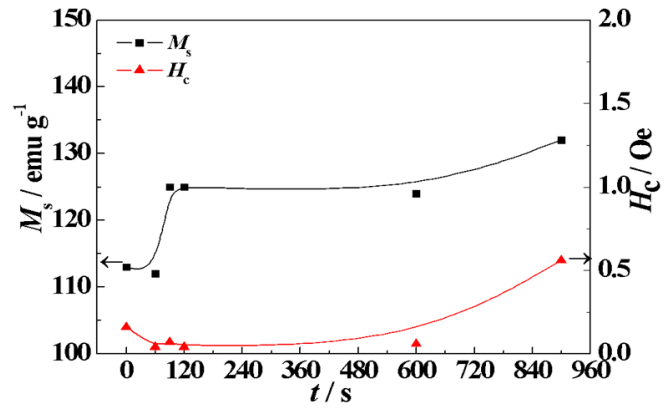

(b)

Figure 7. Magnetization hysteresis curves taken from the $\left(\mathrm{Fe}_{0.4} \mathrm{Co}_{0.6}\right)_{79} \mathrm{Nb}_{3} \mathrm{~B}_{18}$ alloys annealed at $764 \mathrm{~K}$ (a) and the variation of $M_{\mathrm{S}}$ and $H_{\mathrm{c}}$ as a function of incubation time $t$ (b).

Figure 8 displays the $M-H$ curves of the $\left(\mathrm{Fe}_{0.4} \mathrm{Co}_{0.6}\right)_{79} \mathrm{Nb}_{3} \mathrm{~B}_{18}$ alloys annealed at $764 \mathrm{~K}, 800 \mathrm{~K}$, $880 \mathrm{~K}, 974 \mathrm{~K}$, and $1151 \mathrm{~K}$ for $90 \mathrm{~s}$, respectively. The insert clearly shows the relationship between $M_{\mathrm{s}}$ 
and $H_{\mathrm{c}}$ and annealing temperature. The VSM results indicate that the saturation magnetization $\left(M_{\mathrm{S}}\right)$ increases first and then decreases with the increase of annealing temperature. The alloys annealed at $880 \mathrm{~K}$ exhibit the optimized soft magnetic properties with high $M_{\mathrm{s}}$ of $145 \mathrm{emu} \mathrm{g}^{-1}$ and low $H_{\mathrm{c}}$ of 0.04 Oe. The $\alpha-(\mathrm{Fe}, \mathrm{Co})$ and $\mathrm{Fe}_{23} \mathrm{~B}_{6}$ phases are ferromagnetic $[17,23]$, while $\mathrm{Fe}_{2} \mathrm{~B}$ or $\mathrm{Fe}_{3} \mathrm{~B}$ phases belong to the hard magnetic phase [14]. During the annealing process, more and more short-range ordered clusters are formed within the amorphous matrix, and the coupling of these clusters leads to anisotropy. With the increase of annealing temperatures ranging from $764 \mathrm{~K}$ to $880 \mathrm{~K}$, the crystallization products remain the same, while the mean grain size decreases. The ferromagnetic exchange between these $\alpha-\mathrm{Fe}(\mathrm{Co})$ nanocrystals is enhanced, thus leading to an increase of $M_{\mathrm{s}}$. However, further increase of the annealing temperature results in coarse crystals with the precipitation of hard magnetic phases $\mathrm{Fe}_{2} \mathrm{~B}$ or $\mathrm{Fe}_{3} \mathrm{~B}[24,25]$. As a result, the $M_{\mathrm{S}}$ value of the alloys is found to decrease.

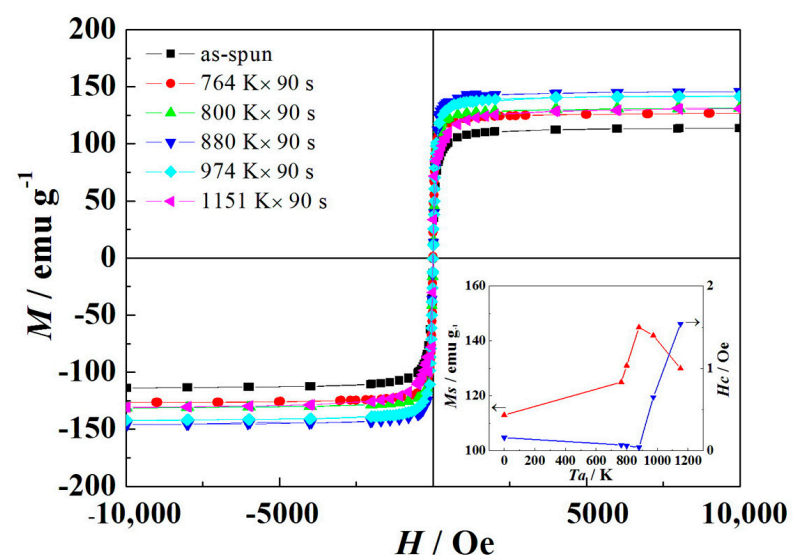

Figure 8. Room-temperature magnetization hysteresis curves for the $\left(\mathrm{Fe}_{0.4} \mathrm{Co}_{0.6}\right)_{79} \mathrm{Nb}_{3} \mathrm{~B}_{18}$ alloys annealed at different temperatures.

According to the random anisotropy model (RAM) proposed by Hezer [26], the coercivity $H_{\mathrm{c}}$ is expressed as follows:

$$
H_{\mathrm{c}} \approx p_{\mathrm{c}} \frac{K_{1}^{4} D^{6}}{J_{\mathrm{s}} A^{3}}
$$

where $p_{\mathrm{c}}$ is the dimensionless pre-factor of the order of unity, $K_{1}$ is the magneto-crystalline anisotropy, $A$ is exchange stiffness, and $J_{\mathrm{s}}$ is saturation polarization.

The coercivity of the annealed $\left(\mathrm{Fe}_{0.4} \mathrm{Co}_{0.6}\right)_{79} \mathrm{Nb}_{3} \mathrm{~B}_{18}$ alloys is quite low. Similar results were also obtained in the $\mathrm{Fe}_{74} \mathrm{Cu}_{0.8} \mathrm{Nb}_{2.7} \mathrm{Si}_{15.5} \mathrm{~B}_{7}$ alloys reported by Hoque et al. [27]. The coercivity of the annealed $\left(\mathrm{Fe}_{0.4} \mathrm{Co}_{0.6}\right)_{79} \mathrm{Nb}_{3} \mathrm{~B}_{18}$ alloys decreases first and then increases with the increase of annealing temperature. With the increase of annealing temperatures in the range of 764-880 K, the crystallization products remain the same, and mean grain size decreases, leading to a decrease of $H_{\mathrm{c}}$ value. However, a further increase of annealing temperature results in the formation of the $\mathrm{Fe}_{2} \mathrm{~B}$ or $\mathrm{Fe}_{3} \mathrm{~B}$ phases. It is reported that the $K_{1}$ values for the $\mathrm{Fe}_{2} \mathrm{~B}$ or $\mathrm{Fe}_{3} \mathrm{~B}$ phases are equal to $430 \mathrm{~kJ} / \mathrm{m}^{3}$ [24,27], which are larger than that of the $\alpha-\mathrm{Fe}(\mathrm{Co})$ phase. Therefore, this increase would significantly increase the magneto-crystalline anisotropy, thus leading to an increase of $H_{\mathrm{c}}$ value.

\section{Conclusions}

(1) During the crystallization process in the $\left(\mathrm{Fe}_{0.4} \mathrm{Co}_{0.6}\right)_{79} \mathrm{Nb}_{3} \mathrm{~B}_{18}$ alloys, a mixture of $\alpha-\mathrm{Fe}(\mathrm{Co}), \mathrm{Fe}_{2} \mathrm{~B}$, and $\mathrm{Fe}_{23} \mathrm{~B}_{6}$ phases is first precipitated from the amorphous matrix, and then the formation of $\alpha$ - $\mathrm{Fe}(\mathrm{Co}), \mathrm{Fe}_{2} \mathrm{~B}$, and $\mathrm{Fe}_{3} \mathrm{~B}$ phases occurs due to the decomposition of the metastable $\mathrm{Fe}_{23} \mathrm{~B}_{6}$ phase.

(2) For alloys annealed at $T_{g} \sim T_{x 1}$, as the incubation time increases, the saturation magnetization first remains unchanged, and then increases steadily, while the coercivity decreases first and then increases. 
(3) The mean grain sizes of the annealed $\left(\mathrm{Fe}_{0.4} \mathrm{Co}_{0.6}\right)_{79} \mathrm{Nb}_{3} \mathrm{~B}_{18}$ alloys first decrease and then increase with the increase of annealing temperature. The mean grain size reaches the minimum value of $12.7 \mathrm{~nm}$ for alloys annealed at $880 \mathrm{~K}$.

(4) The annealed $\left(\mathrm{Fe}_{0.4} \mathrm{Co}_{0.6}\right)_{79} \mathrm{Nb}_{3} \mathrm{~B}_{18}$ alloys exhibit excellent magnetic properties with high saturation magnetization and low coercivity. With the increase of annealing temperature, the saturation magnetization first increases and then decreases, while coercivity is not obviously enhanced. The alloys annealed at $880 \mathrm{~K}$ with the finest grain size exhibit the optimized soft magnetic properties.

Author Contributions: Y.F., M.Z., and L.Y. conceived and designed the experiments; M.Z., Z.J., and F.C. supervised the whole project and gave advice on manuscript editing; Y.F. and P.T. performed the experiments and analyzed the data; the final manuscript was edited by all the authors.

Funding: This research was funded by the National Natural Science Foundation of China (Nos. 51301125, 51371133); the Key Laboratory Scientific Research Program of Education Department of Shaanxi Province, China (No. 17KS055); and China Scholarship Council (CSC).

Conflicts of Interest: The authors declare no conflict of interest.

\section{References}

1. Yoshizawa, Y.; Oguma, S.; Yamauchi, K. New Fe-based soft magnetic alloys composed of ultrafine grain structure. J. Appl. Phys. 1988, 64, 6044-6066. [CrossRef]

2. Rizal, C.; Kolthammer, J.; Pokharel, R.K.; Choi, B.C. Magnetic properties of nanostructured Fe-Co alloys. J. Appl. Phys. 2013, 113, 113905. [CrossRef]

3. Inoue, A.; Shen, B.L.; Koshiba, H.; Kato, H.; Yavari, A.R. Cobalt-based bulk glassy alloy with ultrahigh strength and soft magnetic properties. Nat. Mater. 2003, 2, 661-663. [CrossRef] [PubMed]

4. Willard, M.A.; Laughlin, D.E.; McHenry, M.E.; Thoma, D.; Sickafus, K.; Cross, J.O.; Harris, V.G. Structure and magnetic properties of $\left(\mathrm{Fe}_{0.5} \mathrm{Co}_{0.5}\right)_{88} \mathrm{Zr}_{7} \mathrm{~B}_{4} \mathrm{Cu}_{1}$ nanocrystalline alloys. J. Appl. Phys. 1998, 84, 6773-6777. [CrossRef]

5. McHenry, M.E.; Willard, M.A.; Laughlin, D.E. Amorphous and nanocrystalline materials for applications as soft magnets. Prog. Mater. Sci. 1999, 44, 291-433. [CrossRef]

6. Tang, J.C.; Mao, X.Y.; Li, S.D.; Gao, W.L.; Du, Y.W. Effects of two-step annealing on the microstructures and soft magnetic properties of nanocrystalline $\mathrm{Fe}_{86} \mathrm{Zr}_{7} \mathrm{~B}_{6} \mathrm{Cu}_{1}$ ribbons. J. Alloys Compd. 2004, 375, 233-238. [CrossRef]

7. Cao, C.C.; Fan, J.W.; Zhu, L.; Meng, Y.; Wang, Y.G. Effects of relaxation time on local structural and magnetic properties of $\mathrm{Fe}_{80.8} \mathrm{~B}_{10} \mathrm{P}_{8} \mathrm{Cu}_{1.2}$ amorphous alloy. Acta Phys. Sin. 2017, 66, 167501. (In Chinese)

8. Fan, X.D.; Zhang, T.; Jiang, M.F.; Yangc, W.M.; Shen, B.L. Synthesis of novel FeSiBPCCu alloys with high amorphous forming ability and good soft magnetic properties. J. Non-Cryst. Solids 2018, in press. [CrossRef]

9. Parsons, R.; Zang, B.; Onodera, K.; Kishimoto, H.; Kato, A.; Suzuki, K. Soft magnetic properties of rapidly-annealed nanocrystalline Fe-Nb-B-(Cu) alloys. J. Alloys Compd. 2017, 723, 408-417. [CrossRef]

10. Xue, L.; Yang, W.M.; Liu, H.S.; Men, H.; Wang, A.; Chang, C.T.; Shen, B.L. Effect of Co addition on the magnetic properties and microstructure of FeNbBCu nanocrystalline alloys. J. Magn. Magn. Mater. 2016, 419, 198-201. [CrossRef]

11. Ramanujan, R.V.; Zhang, Y.R. Quantitative transmission electron microscopy analysis of the nanocrystallization kinetics of soft magnetic alloys. Phys. Rev. B 2006, 74, 224408. [CrossRef]

12. Kotan, H.; Darling, K.A.; Saber, M.; Scattergood, R.O.; Koch, C.C. An in situ experimental study of grain growth in a nanocrystalline $\mathrm{Fe}_{91} \mathrm{Ni}_{8} \mathrm{Zr}_{1}$ alloy. J. Mater. Sci. 2013, 48, 2251-2257. [CrossRef]

13. Sahoo, T.; Majumdar, B.; Srinivas, V.; Srinivas, M.; Nath, T.K.; Agarwal, G. Improved magnetoimpedance and mechanical properties on nanocrystallization of amorphous $\mathrm{Fe}_{68.5} \mathrm{Si}_{18.5} \mathrm{Cu}_{1} \mathrm{Nb}_{3} \mathrm{~B}_{9}$ ribbons. J. Magn. Magn. Mater. 2013, 343, 13-20. [CrossRef]

14. Xue, L.; Liu, H.S.; Dou, L.T.; Yang, W.M.; Chang, C.T.; Inoue, A.; Wang, X.M.; Li, R.W.; Shen, B.L. Soft magnetic properties and microstructure of $\mathrm{Fe}_{84-x} \mathrm{Nb}_{2} \mathrm{~B}_{14} \mathrm{Cu}_{x}$ nanocrystalline alloys. Mater. Design 2014, 56, 227-231. [CrossRef] 
15. Li, P.; Su, H.L.; Song, Y.J.; Wu, Y.C. Effects of annealing temperature on microstructure and magnetic properties of $\mathrm{Fe}_{73.37} \mathrm{Cu}_{0.92} \mathrm{Nb}_{2.9} \mathrm{Si}_{13.56} \mathrm{~B}_{9.24}$ amorphous alloy. Mater. Sci. Technol. 2013, 29, 460-463. [CrossRef]

16. Jiang, J.Z. Anomalous grain growth in nanocrystalline $\mathrm{Fe}_{73.5} \mathrm{Cu}_{1} \mathrm{Nb}_{3} \mathrm{Si}_{13.5} \mathrm{~B}_{9}$ alloys. Nanostruct. Mater. 1997, 9, 245-248. [CrossRef]

17. Stoica, M.; Kumar, S.; Roth, S.; Ram, S.; Eckert, J.; Vaughan, G.; Yavari, A.R. Crystallization kinetics and magnetic properties of $\mathrm{Fe}_{66} \mathrm{Nb}_{4} \mathrm{~B}_{30}$ bulk metallic glass. J Alloys Compd. 2009, 483, 632-637. [CrossRef]

18. Torrens-Serra, J.; Rodríguez-Viejo, J.; Clavaguera-Mora, M.T. Nanocrystallization kinetics and glass forming ability of the $\mathrm{Fe}_{65} \mathrm{Nb}_{10} \mathrm{~B}_{25}$ metallic alloy. Phys. Rev. B 2007, 76, 214111. [CrossRef]

19. Imafuku, M.; Sato, S.; Koshiba, H.; Matsubara, E.; Inoue, A. Crystallization behavior of amorphous $\mathrm{Fe}_{90-\mathrm{X}} \mathrm{Nb}_{10} \mathrm{~B}_{\mathrm{X}}(\mathrm{X}=10$ and 30) alloys. Mater. Trans. JIM 2000, 41, 1526-1529. [CrossRef]

20. Yao, B.; Guo, H.C.; Wang, J.; Ding, B.Z.; Li, H.; Wang, A.M.; Hu, Z.Q. Influence of pressure on the grain sizes in the crystallization process of an amorphous Fe-Mo-Si-B alloy. Phys. B Condens. Matter 1996, 228, 379-382. [CrossRef]

21. Yang, W.M.; Liu, H.S.; Dun, C.C.; Zhao, Y.C.; Dou, L.M. The mechanism of the anomalous variation of grain size for Fe-based nanocrystalline alloys. Acta Phys. Sin. 2012, 61, 106802. (In Chinese)

22. Guo, Y.C.; Wang, Z.X. Amorphous State Physics, 1st ed.; Scientific Press: Beijing, China, 1984; pp. $129-145$. (In Chinese)

23. Shen, B.L.; Men, H.; Inoue, A. Fe-based bulk glassy alloy composite containing in situ formed á-(Fe, Co) and $(\mathrm{Fe}, \mathrm{Co})_{23} \mathrm{~B}_{6}$ microcrystalline grains. Appl. Phys. Lett. 2006, 89, 101915. [CrossRef]

24. Gao, J.E.; Li, H.X.; Jiao, Z.B.; Wu, Y.; Chen, Y.H.; Yu, T.; Lu, Z.P. Effects of nanocrystal formation on the soft magnetic properties of Fe-based bulk metallic glasses. Appl. Phys. Lett. 2011, 99, 052504. [CrossRef]

25. Zhu, M.; Fa, Y.; Jian, Z.Y.; Yao, L.J.; Jin, C.Q.; Nan, R.H.; Chang, F.E. Non-isothermal crystallization kinetics and soft magnetic properties of the $\mathrm{Fe}_{67} \mathrm{Nb}_{5} \mathrm{~B}_{28}$ metallic glasses. J. Therm. Anal. Calorim. 2018, 132, 173-180. [CrossRef]

26. Hezer, G. Grain size dependence of coercivity and permeability in nanocrystalline ferromagnets. IEEE Trans. Magn. 1990, 26, 1397-1402. [CrossRef]

27. Hoque, M.S.; Hakim, M.A.; Dhar, U.; Saha, D.K.; Nordblad, P.; Paul, D.P. Detailed study of ultra-soft magnetic properties of $\mathrm{Fe}_{74} \mathrm{Cu}_{0.8} \mathrm{Nb}_{2.7} \mathrm{Si}_{15.5} \mathrm{~B}_{7}$. Philos. Mag. 2011, 91, 2117-2139. [CrossRef]

(C) 2018 by the authors. Licensee MDPI, Basel, Switzerland. This article is an open access article distributed under the terms and conditions of the Creative Commons Attribution (CC BY) license (http:// creativecommons.org/licenses/by/4.0/). 